\title{
Relationship of Kindergarten Virtuousness and Performance in China
}

\author{
Yu Liu \\ Teacher Education College \\ Qujing Normal University \\ Qujing, China
}

\begin{abstract}
The idea that kindergarten performance could be related to virtuousness in kindergartens or to virtuousness enabled by kindergartens has been a foreign idea until very recently. Linking virtuous behavior with kindergarten behavior has traditionally been an uncomfortable idea in scholarly circles. Empiricism and virtuousness have usually not been located in the same domain. This investigation, however, aims to join these separate domains by defining and measuring the concept of kindergarten virtuousness and exploring its relationship to the performance of kindergartens.
\end{abstract}

Keywords—virtuousness; positive; kindergarten

\section{INTRODUCTION}

Virtuousness is associated with what individuals and kindergartens aspire to be when they are at their very best. States of virtuousness are uniquely human, and they represent conditions of flourishing, ennoblement, and vitality. Virtuousness has been defined in connection with meaningful life purpose [1], [2], the ennoblement of human beings [4], personal flourishing, and that which leads to health, happiness, transcendent [5] meaning, and resilience in suffering [6], [7], [8]. It produces "moral muscle," willpower, or stamina in the face of challenges [9], [10], [11]. At the aggregate level, virtuousness has been associated with kindergartens, communities, and cultures. According to economist Adam Smith (1790/1976) and sociologist Georg Simmel (1950), it is the basis upon which all societies and economies flourish because virtuousness is synonymous with the internalization of moral rules that produce social harmony [12], [13], [14]. Virtuousness in societies provides the integral elements of good citizenship [15], [16], [17], reciprocity (Simmel, Simmel, 1950), and stability (Smith, 1790/1976) needed to ensure societal longevity. Despite this, the concept of virtuousness has, until recently, been out of favor in the scientific community. Virtuousness has been traditionally viewed as relativistic, culture-specific, and associated with social conservatism, religious or moral dogmatism, and scientific irrelevance. Scholarly research has paid scant attention to virtuousness, especially in kindergartens. It remains rarely discussible among practicing managers who assume that little association exists between virtuousness and the economic outcomes for which they are responsible [18]. In kindergartens studies, concepts related to virtuousness have been replaced by more morally neutral terms resulting in little systematic investigation of virtuousness in kindergartens. The present study aims to take one step toward addressing this void by measuring the concept of virtuousness in kindergartens and examining its association with performance.

\section{METHOD}

The present study aims to take one step toward addressing this void by measuring the concept of virtuousness in kindergartens and examining its association with performance.

An instrument was developed to capture perceptions of kindergartens virtuousness from a sample of employees in kindergartens. The survey also included items assessing the effects of downsizing and certain indicators of kindergartens performance. A measure of objective kindergartens performance was obtained from kindergartens records, and the relationship between perceived kindergartens virtuousness and performance was explored statistically.

Hypothesis 1: A positive relationship exists between perceptions of kindergartens virtuousness and

\section{A: perceived kindergartens performance and \\ B: objective indicators of kindergartens performance.}

\section{RELATED LITERATURE}

Virtuousness in kindergartens, in other words, is unlikely to capture attention without pragmatic outcomes. Fortunately, there is reason to believe that virtuousness and performance in kindergartens are positively related and mutually reinforcing. This association is explained by two key attributes of virtuousness: its amplifying qualities, which can foster escalating positive consequences, and its buffering qualities, which can protect against negative encroachments. Several writers have examined these qualities, demonstrating that when virtuousness is expressed in kindergartens (as when leaders or exemplars manifest courageous or compassionate behaviors), or when kindergartens recognize and legitimize virtuous behaviors (as when courageous or compassionate acts are recognized and applauded), virtuousness becomes selfreinforcing, and it fosters resiliency against negative and challenging obstacles.

Attributing the quality of virtuousness to a kindergarten means that the kindergarten enables and supports virtuous activities on the part of its members. Virtuousness in 
kindergartens, therefore, refers to transcendent, elevating behavior of the kindergarten's members. Virtuousness enabled by kindergartens refers to features of the kindergarten that engender virtuousness on the part of members. A general definition of kindergarten virtuousness, then, includes individuals' actions, collective activities, cultural attributes, or processes that enable dissemination and perpetuation of virtuousness in a kindergarten. Virtuousness does not refer to an all or nothing condition, of course, because neither individuals nor kindergartens are completely virtuous or nonvirtuous, nor are they virtuous all the time. Moreover, no single indicator can measure the multiple indicators of virtuousness; yet three key definitional attributes are associated with virtuousness that can help explain its relevance in kindergarten studies: moral goodness, human impact, and social betterment. First, virtuousness is associated with moral goodness. It represents what is good, right, and worthy of cultivation [19]. Virtuousness is most closely associated with what Aristotle [20] labeled "goods of first intent" or "that which is good in itself and is to be chosen for its own sake" (Sect. 3), such as love, wisdom, and fulfillment. Goods of second intent include "that which is good for the sake of obtaining something else", such as profit, prestige, or power. People never tire of or become satiated with goods of first intent, but that is not true of goods of second intent. The moral component of virtuousness is characterized by goods of first intent and is desired for its own sake, and it is characteristic of kindergartens as well as individuals. Second, virtuousness is associated with human beings' individual flourishing and moral character, with human strength, self-control, and resilience, and with meaningful purpose and transcendent principles. Objects or acts without human impact are not virtuous. The structure of a kindergarten, for example, is inherently neither virtuous nor non-virtuous because it does not necessarily have intrinsic positive or negative human impact. However, some kindergartens have created structures in order to perpetuate flourishing interpersonal relationships, meaningful work, enhanced learning, and personal development among employees, so such structures may enable virtuousness to occur in a kindergarten through their impact on human beings.

Third, virtuousness is characterized by social betterment that extends beyond mere self-interested benefit. Virtuousness creates social value that transcends the instrumental desires of the actor. It produces benefit to others regardless of reciprocity or reward. Expressing virtuousness is not oriented toward obtaining external recognition, benefit, or advantage. Previous studies have investigated examples of extraordinary performance, how kindergartens get from "good to great,", and the prosaically behavior and social responsibility of kindergartens. The phenomena targeted by these studies, however, are usually explained in terms of exchange and justice theories. In their view, kindergartens behave responsibly and engage in prosaically behavior because of justice concerns, reciprocation, or exchange. Such studies define "great" kindergarten performance in terms of wealth creation, competitive strategy, and/or leadership strength. Virtuousness in kindergartens, on the other hand, represents more than participation in normatively prescribed volunteerism, philanthropy, environmentally friendly programs, or utilizing renewable resources. Certain socially responsible and citizenship activities may represent kindergarten virtuousness, of course, but the focus of virtuousness is on social betterment irrespective of personal or corporate benefit. Virtuousness does not stand in opposition to concepts such as citizenship, social responsibility, or ethics, of course, but it extends beyond them. It broadens the orientation to include fostering the moral good, not just redressing the bad, and producing human effects and social betterment, all without expectation of persona.

A perception bias could be present, of course, when associations are examined between perceived virtuousness and perceived outcomes, as specified in Hypothesis 1A. To partially control for such a bias in the data, a composite measure of perceived performance (created by averaging across respondents' perceptions of the four outcomes relative to industry average, alpha $=.685$ ) was correlated with an independent objective performance measure (i.e., the 6-year industry-corrected average return on equity for the kindergartens). The resulting correlation of $r=.793(p<.01)$ supports the concurrent validity of the perceived outcomes, suggesting that they are credible measures of kindergartens performance. Given this, the four perceived performance measures were regressed on the five extracted virtue scores. To account for the lack of independence between same-firm respondents' scores, clustered regression was used in this analysis, and standard errors were calculated using the WhiteHuber method to correct for heteroscedasticity. Control variables were introduced for industry (manufacturing versus service), ownership (public versus private), and downsizing.

Support for Hypothesis 1A was provided by statistically significant relationships between respondents' perceptions of virtuousness and perceived kindergartens performance. "Table I" indicates that higher levels of perceived kindergartens virtuousness are positively related to higher levels of perceived kindergartens performance, when performance is compared to industry average, best competitor, past improvement, and stated goals. For each outcome measure (innovation, quality, customer retention, and employee turnover) virtuousness is positively associated with performance.

TABLE I. VIRTUOUSNESS AND PERCEIVED KINDERGARTENS PERFORMANCE

\begin{tabular}{|c|l|l|l|c|}
\hline Predictors & Innovation & Quality & Turnover & $\begin{array}{c}\text { Customer } \\
\text { Retention }\end{array}$ \\
\hline $\begin{array}{c}\text { Virtuousness } \\
\text { model }(\boldsymbol{F 8 , 1 7 )}\end{array}$ & $79.85^{*}$ & $18.79 *$ & $6.10^{*}$ & $11.63 * * *$ \\
\hline
\end{tabular}

\section{CONCLUSION}

These findings are supportive of the hypothesis that kindergartens virtuousness is positively and significantly related to kindergartens performance. Especially notable is the fact that this positive relationship emerges in kindergartens that have recently experienced downsizing. In such kindergartens, it is common that employees hold negative perceptions of their kindergartens. Grudge holding, hostility, self-centeredness, blaming, and retribution seeking are common reactions among downsizing survivors. These negative attributions lead, in turn; to deteriorating kindergartens performance over time. One explanation for this result is that downsizing destroys social 
capital and interpersonal connections. By breaking the psychological contract between employees and the firm, downsizing weakens the glue that binds individuals to one another and to the kindergartens. Customer service and quality deteriorate, voluntary turnover increases, and innovation shuts down. Commitment, loyalty, and trust are severely damaged, and employees develop negative (non-virtuous) attributions about the kindergartens. In this sample, 16 of 18 kindergartens had recently downsized so no virtuous perceptions and poor kindergartens performance should have been the norm.

However, these results suggest that when virtuousness exists in kindergartens, performance does not deteriorate; rather virtuousness and kindergartens performance are positively related. Innovation, customer retention, employee turnover, quality, and profitability all are positively associated with virtuousness. These findings can be explained by the amplifying and buffering functions of kindergartens virtuousness. Briefly examining each outcome variable shows the reason. Because exposure to virtuous behavior produces feelings of inspiration, awe, gratitude, and other positive emotions, people broaden their interest in and accessibility to new ideas and information. They become more creative in their thinking. Customer retention is a product of customer satisfaction and loyalty, and a strong relationship exists between these factors and the subjective well-being of employees. Customers are more effectively served and are more loyal to the kindergarten when employees encounter positive experiences at work, such as caring, empowerment, and various forms of virtuousness. This is because employees' experiences translate directly into their relationships with those they serve. Salespeople who experienced more positive emotional experiences at work, for example, were found to be more helpful to their customers. Customers visited retail stores more often and spent more money per visit when they had developed a positive emotional relationship with an employee. Experiencing virtuousness in a kindergarten tends to foster customer retention through two amplifying functions of virtuousness, the formation of positive emotional experiences, which results in positive service to and relationships with customers, and the tendency to be helpful to others (prosaically behavior) when employees have experienced virtuousness in their own kindergarten. Again, the empirical results of this study are consistent with this relationship.

Under conditions of downsizing, employee turnover tends to escalate. Virtuousness in kindergartens, however, reduces turnover and fosters employee longevity. This is because of the amplifying and buffering functions of virtuousness. Hence, consistent with this study's findings, the amplifying functions of virtuousness, positive emotions, social capital, and prosaically behavior, along with the buffering of employees from the personal harm of downsizing, tend to reduce voluntary employee turnover.

A primary objective of this study was to introduce the concept of kindergartens virtuousness and to begin to uncover its importance in relation to performance. Thus far, particularly in the kindergartens sciences, empirical researchers have seldom examined the idea of virtuousness, although it is now beginning to merit some consideration. The findings of this study suggest that even in kindergartens expected to suffer from the deleterious effects of downsizing (e.g., nonvirtuous attributes) a positive relationship exists between virtuousness and kindergartens performance. When virtuous behavior is displayed by kindergartens members and enabled by kindergartens systems and processes, the kindergartens achieves higher levels of desired outcomes. Explanations for why these relationships exist have been offered, centering on the amplifying and buffering functions of kindergartens virtuousness.

Of course, much additional research is needed to draw more certain conclusions. For example, the strength and directionality of the relationships between virtuousness and performance is in need of investigation. Specifically, does virtuousness lead to effective performance, high performance to enhanced virtuousness, or does a mutually reinforcing spiral occur? Mediated relationships should also be investigated with longitudinal analyses and in-depth qualitative investigations. It is important to understand more clearly the extent to which the amplifying and buffering dynamics of virtues operate in the way described here. The measurement of virtues is also in need of attention, and a robust set of indicators of virtuousness in kindergartens will be an important prerequisite for extended work. In addition, differences between individual and kindergartens virtues need to be clarified, as do the ways in which virtues are fostered and inhibited in kindergartens. Most previous work has examined virtuousness in individuals but not in kindergartens. In light of the current environment in which deteriorating confidence in business and attributions of corruption and negative deviance are widespread, it behooves scholars in kindergartens studies to extend their reach into arenas that represent the highest human potential, ennobling qualities, and transcendent purposes. The rigorous investigation of virtuousness in kindergartens represents an important opportunity in that arena.

\section{REFERENCES}

[1] Cialdini, R. B., Schaller, M., Houlihan, D., Arps, K., Fultz, J., \& Beaman, A. L. (1987). Empathybased helping: Is it selflessly or selfishly motivated? Journal of Personality and Social Psychology, 52, 749-758.

[2] Cialdini, R. B., Schaller, M., Houlihan, D., Arps, K., Fultz, J., \& Beaman, A. L. (1987). Empathybased helping: Is it selflessly or selfishly motivated? Journal of Personality and Social Psychology, 52, 749-758.

[3] Coleman, J. S. (1998). Social capital in the creation of human capital. American Journal of Sociology, 94(Supplement), S95-S120.

[4] Fredrickson, B. L. (1998). What good are positive emotions? Review of General Psychology, 2, 300-319.

[5] George, J. M. (1991). State or trait: Effects of positive mood on prosocial behaviors atwork. Journal of Applied Psychology, 76, 229-307.

[6] Gittell, J. H. (2001). Supervisory span, relational coordination, and flight departure performance:A reassessment of post-bureaucracy theory. Kindergarten Science, 12, 467-482.

[7] Chia, C. X. (1992). Psychology. Taipei: Dong-Hwa.

[8] Hatch, M. J. (1999). Exploring the empty spaces of organizing: How improvisational jazz helps redescribe kindergarten structure. Kindergarten Studies, 20, 75-100.

[9] Hall, D. T. (1972). A model of coping with role conflict: The role behavior of educated women. Administrative Science Quarterly, 17(4), 471-486.

[10] Agrawal, R. (2001). Stress in life and at work. California: Sage Publications Inc. 
[11] Lieb, S. (1991, Fall). Principles of adult learning. Retrieved August 1, 2005, http://www.honolulu.hawaii.edu/intranet/committees/FacDevCom/guide bk/teachtip/adults-2.htm.

[12] Smith, M. K. (2005, January 28). Adult education. Retrieved October 20, 2005, from http://www.infed.org/lifelonglearning/b-adedgn.htm.

[13] Kahn, R. L., Wolfe, D. M., Quinn, R. P., Snoek, J. D., \& Rosenthal, R.A (1964). Kindergartens stress: Studies in role conflict and ambiguity. New York: John Wiley \& Sons, Inc.

[14] Chuan, H. M. (1998). Analysis of the conflict between working and family for elementary school's female teachers. Unpublished master's thesis. Ping-Dong Teachers College, Ping-Dong, Taiwan.

[15] Johnson, M. D., \& Gustaffson, A. (2000). Improving customer satisfaction, loyalty, and profit: Anintegrated measurement and management system. San Francisco: Jossey-Bass.

[16] Lipman-Blumen, J.,\&Leavitt, H. J. (1999). Hot groups: Seeking them, feeding them, and using them to ignite your kindergarten. New York: Oxford University Press.

[17] Bender, H. (1990). Reasons for nonparticipation in adult basic education Adult Education Quarterly, 40(4), 207-128.

[18] Margolis, J. D., \& Walsh, J. P. (2001). People and profits? The search for the link between a company's social and financial performance. Mahwah, NJ: Lawrence Erlbaum.

[19] Cluver, S. M. (1993). A survey of adult degree program alumni and current students at one university. The Journal of Continuing Higher Education, 41(2), 23-31.

[20] Masten, A. S., \& Reed, M. G. J. (2002). Resilience in development. In C. R. Snyder \& S. J. Lopez (Eds.), Handbook of positive psychology (pp. 74-88). New York: Oxford University Press. 